\title{
Television Tip Overs and Head Traumas in Childhood: Results of 36 Children from a Reference Center in Central Anatolia, Turkey
}

\author{
Ahmet KUCUK, Abdulfettah TUMTURK \\ Erciyes University School of Medicine, Department of Neurosurgery, Kayseri, Turkey
}

\section{ABSTRACT}

\begin{abstract}
AIM: Television tip overs and head traumas in children showed an increase in the recent years in Turkey and throughout the world. In this study, the injury types, the surgical interventions and the children exposed to head trauma due to an accident caused by a falling television were investigated retrospectively. Some cautions were suggested in order to prevent these injuries.
\end{abstract}

MATERIAL and METHODS: The gender, age, Pediatric Glasgow Coma Scale (PGCS) score, radiologic findings, the need for intensive care unit, the time period spent in the hospital, the applied surgical treatments, the accompanied treatment and pathology of 36 children who were treated in the department of neurosurgery at Erciyes University School of Medicine were evaluated.

RESULTS: Eighteen of the patients were male and 18 were female. The number of cases younger than 3 years was 21 while the number of cases over the age of 3 years was 15 . Thirty-two of the cases had full head trauma. Three female patients died. The mean PGCS score at admission was 12.7. While surgical treatment was applied to four of the patients in our department, facial nerve exploration was performed in the Ear Nose and Throat Department to the patient who suffered facial nerve damage.

CONCLUSION: Each year, many children are injured or even die due to this trauma that can be easily prevented. The parents, television producers, doctors, health personnel, academic institutions, governments, legislators, national and international organizations are responsible for this trauma.

KEYWORDS: Television, Head trauma, Childhood

\section{INTRODUCTION}

$\mathrm{T}$ Television (TV) is an integral and indispensable part of every household and most of the family activity is centered on it (10). Additionally, children watch more than 28 hours of TV shows a week (1). With the development of the technology in recent years, the dimension of the TV has changed. The former small screened and heavy televisions have been replaced by large sized and relatively heavy plasma or Liquid-crystal-display (LCD) televisions that are often not fixed to a wall or furniture. The existence of TVs in almost all homes constitutes a potential danger for head trauma in the children. In 2006, the United States Consumer Products Safety commission reported increasing number of pediatric deaths related TV trauma (6). After this report, several studies from different countries have confirmed the result and warned that the rate of these injuries is increasing (6). In this study, we presented the clinical conditions and the results of the surgical treatments of the children who suffered head trauma due to the TV accidents and make some recommendations and give social messages to prevent such injuries. 


\section{MATERIAL and METHODS}

This was a retrospective descriptive study conducted among 36 pediatric patients who were admitted to Erciyes University Medical Faculty, Department of Neurosurgery with a TV fall injury between January 2007 and December 2014. The gender, age, pediatric Glasgow Coma Scale (PGCS) score, radiological findings, the need for intensive care unit (ICU), the time period spent in the hospital, the applied surgical treatments, the accompanied treatment and pathology of were evaluated in all patients.

The cases were divided into two groups including the ages of $0-3$ and the ages over 3 years. Patients underwent a physical examination and complete blood count, biochemical analysis, extremities and abdominal X-rays, abdominal ultrasonography and cranial, thoracic and abdominal computerized tomography (CT) were performed. All patients were consulted with orthopedics, neurosurgery and pediatrics.

\section{RESULTS}

The age of the children who were treated in our department due to head trauma following TV tip overs varied between 15 month and 11 years, while the average age was 3.6. Eighteen of the cases $(50 \%)$ were boys while 18 of them $(50 \%)$ were girls. The number of cases who were under the age of 3 was $21(58 \%)$ while the number of cases who were over the age of 3 was $15(42 \%)$. Twelve of the male patients $(66 \%)$ were under the age of three while 6 of them (34\%) were more than 3 years old. 9 of the female cases $(50 \%)$ were under the age of three while 9 of them were older than 3 years (50\%) (Table I).

In 32 of the cases (88\%) only head trauma occurred. In one of the cases, cochlear nerve injury occurred due to temporal bone fracture and the patient was operated by an ear, nose and throat (ENT) team due to hearing loss but significant changes were not observed. In some of the cases facial asymmetry, periorbital ecchymosis and pneumomediastinum occurred, however these cases did not required any surgical treatment and were treated by the medical treatment of the relevant departments.

Within the age group of 0-3 there were 2 girls whose PGCS scores were 3 and another girl (8.3\%) with pneumomediastinum died during the ICU process.

The average of the PGCS was 12.7 in both of the groups. The PGCS of 19 cases (53\%) was 15; in 10 cases $(38.8 \%)$ it was 14 while the PGCS of the other cases was lower (Table II).

When looking at the cranial radiological evaluation of the cases, in 16 of the cases $(44.4 \%)$ there was linear fracture, in 6 cases $(16.6 \%)$ traumatic subarachnoid hemorrhage $(\mathrm{SAH})+$ brain edema occurred, in 3 cases (8.3\%) depressed fracture, in 2 of the cases $(5.5 \%)$ acute subdural hematoma $(\mathrm{ASH})$, and in 1 case $(2.8 \%)$ contusion cerebri occurred. The cranial radiological evaluation of 8 cases was normal.

Fifteen of the patients (41.6\%) were admitted to the neurosurgical ICU. The average time period spent by these patients in the ICU was 10.6 days. The other 21 patients were admitted to the inpatient neurosurgery service. These patients spent an average 3.7 days in the hospital. In two of the patients $(5.5 \%)$ who were accepted to ICU epileptic seizures occurred, while facial asymmetry was observed in another 3 cases (8.3\%).

Surgical treatment was applied to four of the patients $(11.1 \%)$ in our department. Remodelling was performed to three patients for a depressed fracture. In one patient $(2.7 \%)$, an epidural hematoma was evacuated. In two patients, surgical treatment was not needed despite a small ASH.

\section{DISCUSSION}

In recent years, an increase can be observed in the number of the articles associated with head trauma after TV tip overs $(2,3,5-8,10)$. The children aged between 1 and 5 years tend to recognize their surroundings instinctively and to climb on top of things naturally. Therefore they can easily capsize the television over themselves. Despite the growth of the new generation TV screen, the thickness of the screen is decreasing. This feature can change the gravity centre of a television that has not been fixed with even with the smallest impact and can ease the falling of the television. Therefore the TV can fall on top of the children and may cause various injuries and especially head trauma.

In various articles, head trauma after TV tip overs has been reported especially in boys $(4,6,7)$. Although the number of boys and girls was equal in this study, the number of male patients in the cases aged between 0 and 3 is clearly higher (Table I).

Injuries in head traumas following TV tip overs are usually mild but they may be rarely fatal or they may require ICU admission. After the evaluation of the 42 cases of the children who were admitted to the emergency due to TV tip over traumas, Guloglu et al. reported that 16 patients (38.1\%) required ICU, the average of the time period they spent under ICU was 16.2 days, and 5 of the patients (11.9\%) died (5). Rutkoski et al. reported, in their study on 52 patients who were exposed to head trauma after TV tip overs, that 14 patients $(26.9 \%)$ required ICU, the average of the time period they spent in ICU was 2.1 days (1-7 day) and in one of the cases $(1.9 \%)$ the patient died (8). In this study, 15 of the patients were admitted to ICU $(41.6 \%)$. The average time period they spent in the ICU was 10.6 days (2-38 days).

The average time spent in the hospital by the patients who suffered head traumas caused by TV tip over is similar in various articles. It was reported that the patients with head traumas after fall of TV, whose cases were examined in a study by Suresh et al. spent an average of 4 days in the hospital (10), while Mills et al. reported this period as 4.6 days in their own research (6). In our cases the average length of the hospital stay was 3.7 days. When considering these cases, in 16 of the cases $(44.4 \%)$ a linear fracture was reported, in 6 cases $(16.6 \%)$ traumatic $\mathrm{SAH}+$ brain edema occurred, in 3 cases (8.3\%) depressed fracture, in 2 of the cases (5.5\%) ASH and in 1 case $(2.8 \%)$ contusion cerebri was diagnosed. 
Table I: The Distribution of the Cases According to the Age and Gender

\begin{tabular}{cccc}
\hline Age (years) & Boy & Girl & Total \\
\hline $3 \leq$ & $12(33.3 \%)$ & $9(25 \%)$ & $21(58 \%)$ \\
\hline$>3$ & $6(16.7 \%)$ & $9(25 \%)$ & $15(42 \%)$ \\
\hline Total & 18 & 18 & 36 \\
\hline
\end{tabular}

Table II: The Pediatric Glasgow Coma Scale (PGCS) Scores of the Patients

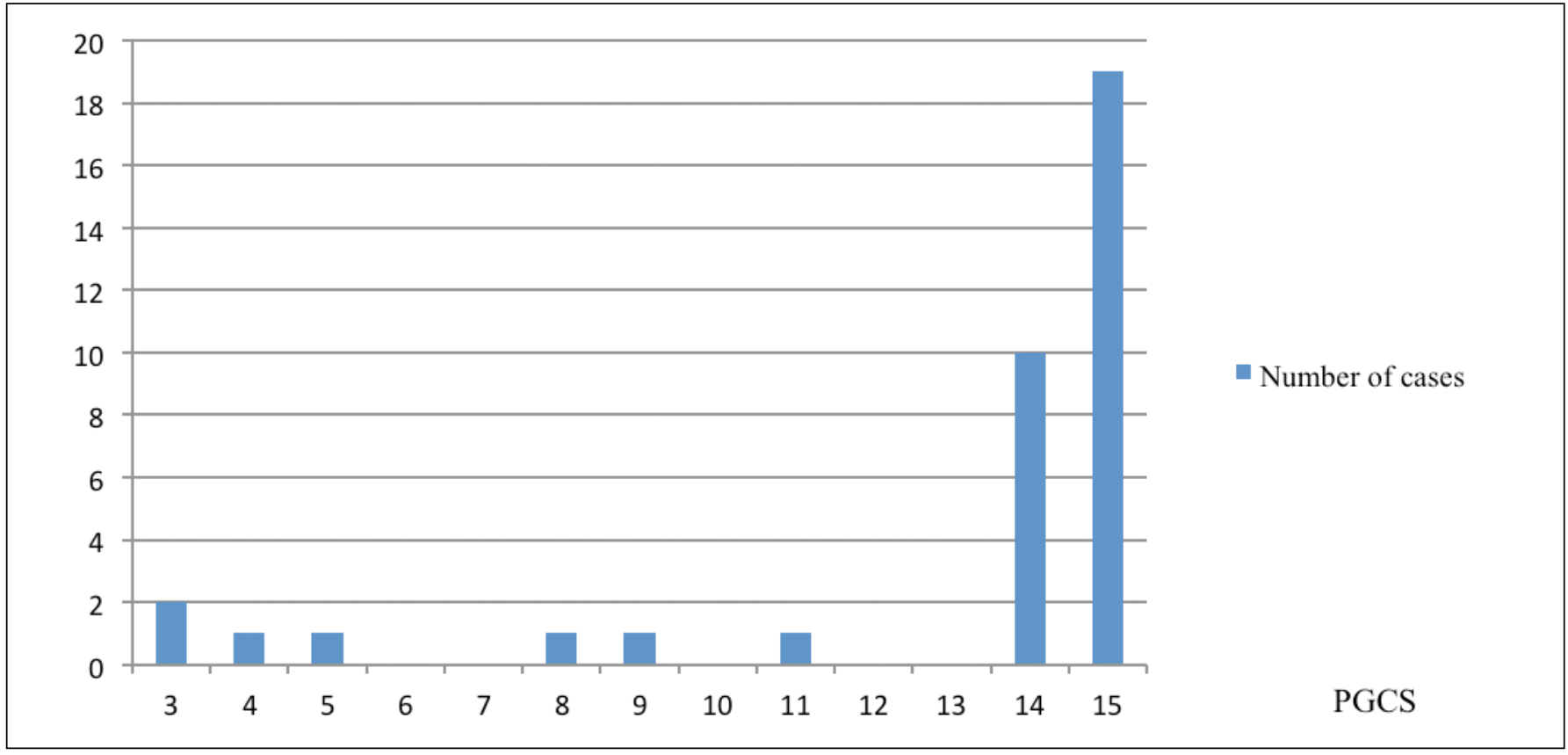

Surgery may be an inevitable consequence of some head trauma after TV tip overs. In a study including 116 pediatric patients conducted by Sikron et al., it was reported that 15 (12.9\%) of the patients required surgical treatment (9). Guloglu et al. reported that 12 of the 42 patients $(28.6 \%)$ with head trauma required surgical treatment (5). In our study, 5 patients (13.8\%) underwent surgical treatment. Three of them had depressed skull fracture, one had epidural hematoma, while the last had facial nerve exploration.

Traumatic brain injury (TBI) is a serious clinical problem associated with head trauma. Unfortunately, 3 girl patients within the group of age 1-3 years died in the ICU due to TBI. The PGCS score in two of these cases was 3 , while in the $3^{\text {rd }}$ case it was 4 . In one of the patients TBI was accompanied by pneumomediastinum.

TV-related head traumas are mostly preventable traumas. It is possible to reduce the number of these injuries with some measures to be taken. The most important of these measures is to fix especially the light-emitting diode (LED) and LCD televisions onto the wall or to the furniture. This is a very cheap and simple method and the TV producers should definitely use it. The purchasers of these televisions should be warned about this issue. Also, educational programs should be broadcasted on television regarding this issue. Even the fixation process could be made compulsory through a law.

Also the physicians who are constantly struggling with the results of trauma should be trained about TVs falling and related head trauma and later they could educate the society. The issue of TV-related traumas should be investigated in scientific conferences and symposiums. The United Nations Children's Fund (UNICEF) works for children's rights, survival, development and protection and can take an active role in preventing these injuries.

\section{CONCLUSION}

Unfortunately, the head injuries after TV tip overs demonstrate an increase in Turkey as well as all over the world. Sad to say, many children are injured or even die due to this trauma that can be easily prevented. TV-related injuries are everyone's responsibility and not only the injured children's or their parents'. TV manufacturers, doctors, health personnel, academic institutions, governments, legislators, national and international children organizations also have responsibility. The prevention of TV-related injuries is cheaper and easier than the treatment of patients who suffer a trauma. 


\section{REFERENCES}

1. AC Nielsen Company: 2010 Report on Television. Available at: http://www.nielsen.com. Accessed June 22, 2011

2. Cusimano MD, Parker N: Toppled television sets and head injuries in the pediatric population: A framework for prevention. J Neurosurg Pediatr 17:3-12, 2016

3. Deisch J, Quinton R, Gruszecki AC: Craniocerebral trauma inflicted by television falls. J Forensic Sci 56:1049-1053, 2011

4. DiScala C, Barthel M, Sege R: Outcomes from television sets toppling onto toddlers. Arch Pediatr Adolesc Med 155:145148, 2001

5. Guloglu R, Sarıcı IS, Bademler S, Emirikci S, Issever H, Yanar $\mathrm{H}$, Ertekin C: Falling television related child injuries in Turkey: 10-year experience. Ulus Travma Acil Cerrahi Derg 18:61-64, 2012
6. Mills J, Grushka J, Butterworth S: Television-related injuries in children-the British Columbia experience. J Pediatr Surg 47:991-995, 2012

7. Muniz AE: Craniofacial injuries from television tip-over. Pediatr Emerg Care 28:52-54, 2012

8. Rutkoski JD, Sippey M, Gaines BA: Traumatic television tipovers in the pediatric patient population. J Surg Res 166:199204, 2011

9. Sikron F, Glasser S, Peleg K: Children injured following TV tipovers in Israel, 1997-2003. Child Care Health Dev 33:4551,2007

10. Suresh N, Harini G, Radhika R, Chidambaram B: Head injuries in children resulting from the fall of television. Indian J Pediatr $77: 459-460,2010$ 